\title{
Good Hospital Governance at the Indonesian Hospital
}

\author{
Abunawas Tjaija ${ }^{1, *}$, Muhammad Sabir ${ }^{2}$, Munawir H. Usman ${ }^{1}$ and \\ Muhammad Ahsan Samad ${ }^{1}$
}

\author{
${ }^{1}$ Public Administration Study Program, Faculty of Social and Political Sciences, Tadulako University, City of \\ Palu, Indonesia \\ ${ }^{2}$ Faculty of Medicine, Tadulako University, City of Palu, Indonesia
}

\begin{abstract}
This study aims to describe the commitment of stakeholders in implementing the Good Hospital Governance policy at the Undata Regional General Hospital, Central Sulawesi Province, Indonesia. The method used is a qualitative exploratory approach with 13 (thirteen) informants who were determined by purposive sampling, the data analysis used was an interactive model data analysis from Miles and Huberman by triangulating methods and data sources. The results showed that the successful implementation of the Good Hospital Governance policy at Undata Hospital, Central Sulawesi Province which was viewed from 6 (six) supporting aspects of the implementation of the Van Metter and Van Horn policies had not been running properly. That is; aspects of resources, aspects of the characteristics of the executing agent, aspects of the attitudes/tendencies (dispositions) of the executing agents, and aspects of the external environment (economic, social, and political). Besides, an implementation must also be supported by the commitment of the owner, board of directors, and management as well as all hospital staff, to implement the principles of transparency, accountability, independence, responsibility, equality, and fairness.
\end{abstract}

Keywords: Commitment, policy implementation, hospitals, good governance.

\section{INTRODUCTION}

In the last decade, the study of health systems has developed gradually as a field, with the increasing participation of several global stakeholders (Van Olmen, Marchal, Van Damme, Kegels, \& Hill, 2012). The structure in which organizations are connected and regulated is governance (Stephen Owusu Afriyie et al., 2020). Health governance can be divided into two: health sector governance and organizational governance (Lipunga, Tchereni, \& Bakuwa, 2019). To achieve its operational objectives, every organization needs a level of governance structure (Stephen Owusu Afriyie, Kong, Danso, Ibn Musah, \& Akomeah, 2019). The combination of the concepts of quality management and governance can ensure proper monitoring of processes and processes that facilitate good governance. This involves the application of clear best practices, adequate representation by stakeholders, and consultation (Arya, 2020). Both public and private hospitals are responsible directly or indirectly to the public and government because they receive public funds to provide health services by engaging in the public insurance system for the provision of health services (Dixit, 2017). The importance of governance in the health system is evident from the fact that most of the conceptualizations and descriptions of health systems developed during the last decade talking about aspects

*Address correspondence to this author at the Soekarno Hatta No. KM. 9, City of Palu, 94148, Indonesia; Tel: +62 811-811-453; Fax: 0451 - 422844;

E-mail: abutjaiyauntad@gmail.com of governance, whether in terms of stewardship, regulation, supervision, or governance itself (Mikkelsen-Lopez, Wyss, \& De Savigny, 2011).

Governance is important when influencing the existence and functioning of various parties in the environment and the factors behind their decisions (Pyone, Smith, \& Van Den Broek, 2017). Concerns about governance stem from conflicts of interest between joint stakeholders. While each stakeholder looks for value for money, consumers have specific goals, which consist of standardized treatment at an adjustable-price (Moro Visconti \& Martiniello, 2019). The main solutions offered to this major challenge center on increasing the capacity of health workers, who in themselves can overcome this challenge to some extent (Oleribe et al., 2019). Good hospital governance is termed Good Hospital Governance (GHG) in the explanation of Law Number 44 of 2009 Article 33 Paragraph (1), that the hospital organization is structured to achieve the hospital's vision and mission by carrying out good corporate governance. good (Good Corporate Governance) and good clinical governance (Good Clinical Governance). District health offices are responsible for providing a range of services tailored to the specific needs of the populations they serve and are expected to lead health care planning from the grassroots level through 'district-led planning' at the lowest level of health care planning in the system (Hanlon et al., 2017).

The concept of Good Hospital Governance (GHG) is the same as the concept of corporate governance in 
general, but its application is adjusted to the type of business, namely in health services. Hospital as a health facility that is engaged in advanced health services (referral) seeks to provide good and quality health services. Good and quality service will automatically bring comfort, patient satisfaction and at the same time will provide a good image advantage for the hospital and the government. In practice, this system must be implemented in every part of the hospital to serve the needs of public health.

In carrying out hospital management, all parties at the leadership and management levels, as well as all medical and non-medical personnel, should carry out their responsibilities to provide services to the community according to their duties and authorities as a form of implementing the principle of responsibility. This principle must also be reflected in the responsiveness and sensitivity of the managers of public agencies to the needs of the community to be served well. This aims to provide excellent health services to patients and is not discriminatory. So that medical and non-medical personnel in the hospital must be professional in serving their patients regardless of their social, economic, and political backgrounds. This equality system must also be practiced in carrying out hospital management in all work units and levels.

\section{METHODS}

The method used is a qualitative exploratory approach with 13 (thirteen) informants who were determined by purposive sampling. This research attempts to explore how weak governance in the public health sector can be transformed into strong governance, and what kind of process (Houngbo et al., 2017) can work from the perspective of employee commitment. This research is qualitative and applies a case study design informed by a multi-level governance approach (Kuhlmann, Rangnitt, \& Von Knorring, 2016).

Three data collection methods were used, namely: participant interviews, direct analysis, and secondary data analysis (Kouam et al., 2014). Interviews were audio-recorded and transcribed before data analysis (Lempp et al., 2018). The content of the interview topic guide addresses questions relating to the level of involvement that exists and its potential benefits in health policymaking and the defense of commitment to policy implementation. This stage should include realistic situation analysis, building commitment, and formulation of a clear plan for integration (Gyapong et al., 2010). This research was conducted in Indonesia, precisely at the Regional General Hospital (RGH), Central Sulawesi Province, Palu City.

\section{RESULTS \& DISCUSSIONS}

The results of interviews with informants, namely:

1. The Director of Undata Hospital regarding the information system conveyed to all employees regarding the implementation of Good Hospital Governance policies at Undata Hospital is as follows: "As a Hospital Director, I always provide information to all staff at Undata Hospital to implement the principles of Good Hospital Governance by doing periodic socialization. Every Monday a morning apple is held which must be attended by all employees. At the time of the ceremony, as much as possible, as the director, I led the ceremony and it became an opportunity for me to socialize with all the staff. However, it is not optimal, because sometimes some staff, especially medical personnel, are not attending doctors".

2. The nurses on duty at Undata Hospital on behalf of WW's initials regarding the socialization of the implementation of Good Hospital Governance at Undata Hospital said as follows: "That there has been no information (implementation of Good Hospital Governance at Undata Hospital), but they also do not know if it is socialized with other nurses, because if we were here, usually when there was socialization it was a representative from each room, usually represented by the head of the room "

3. The Regional Secretary of Central Syulawesi Province, as quoted from the interview as follows: "Indeed, at the time the accreditation was carried out, one of the obstacles that were reported was that Undata Hospital still did not have sub-specialist doctors. Undata and we have also collaborated with several state universities such as Unhas, Wahidin Hospital, and UGM on contract status. The local government does not remain silent for that we always support. Apart from doctors, we also facilitate other health workers to continue their studies to improve human resources. Because the community's complaints are not only on the doctors but also on the hospital services, so we always encourage to increase the capacity of human resources". 
4. In the planning process at Undata Hospital, Mr. $A B$ further conveyed in an interview excerpt as follows: "If you look at the planning process at Undata Hospital, we are doing it based on suggestions from related fields in this hospital, from these suggestions we include it in planning, for example planning for 2021, then all sectors have included their planning needs this year. Because this planning goes through several phased processes, after input from the fields in the hospital and then assistance at Bappeda, the Bappeda Team will filter our planning proposals to see if they match the inputs, outputs, and outcomes and then adjust to the existing budget conditions. This is related to the source of the APBD budget

5. Based on the results of an interview with one of the inpatients with the initials Mrs. HR (67 years) as in the following interview excerpt: "In terms of the waitress, it is quite good, only the toilet is clogged, sorry we are going to operate, if we want to throw it away the water is quite a hassle because it has to be taken out of the room because the toilet here (in the room) is broken and cannot be used. "

6. $\mathrm{HL}$ as the Regional Secretary and Chairman of the Regional Government Budget Team (TAPD) of Central Sulawesi Province as follows: "What is clear is that we hope that the quality of hospital services will be better, secondly all supporting facilities and infrastructure are available, the third is to maintain sustainability. The services of medical personnel, of course, the tools used must be of good quality and in good condition, quality when purchased and in good condition when used, to ensure that the equipment is in good condition, maintenance costs are certainly necessary. The government has allocated funds for the hospital to maintain the equipment and facilities at the hospital, although it is still less. We have also encouraged to give special allocations to hospitals for the maintenance of this equipment. We are also the chairman of TAPD (Regional Government Budget Team) giving the first opportunity to the Health Office and its staff, including the UPT Undata Hospital and Madani Hospital to get sufficient budget to provide the best service to the community".

7. The Head of Functional Medical Staff (SMF) at Undata Hospital revealed the following interview excerpt: "Planning for the need for medical devices at the RSUD has been going well. What is needed by doctors to support services can be fulfilled by the hospital. However, the obstacle faced is the incompatibility of medical device facility planning with human resources, in this case, medical personnel using the equipment. Sometimes medical equipment is available, but there is no one using the tool.

Globally, there is increasing momentum towards alternative insurance programs to consider expanding healthcare services. Part of this approach focuses on health system governance, which can create or determine the successful implementation of health care policies (Abdulmalik, Kola, \&Gureje, 2016). There have been several changes in health care services, which are intended to increase the need for health care institutions to build strong governance mechanisms (Stephen O. Afriyie et al., 2020, Pasinringi et al., 2020). Therefore, it is important for health systems researchers researching governance to provide a consistent and collaborative definition of governance, which will therefore guide the approaches used to analyze governance (Abimbola, Negin, Martiniuk, \& Jan 2017).

When public trust appears to be declining, policymakers take steps to try to restore it. But what does it mean to trust the health system, and how will this definition be encouraged by policymakers seeking to restore lost trust (Abelson, Miller, \& Giacomini, 2009). As the government has been accepted as an important contributor to socio-economic growth, its relevance for the success of the health sector is gradually being recognized in the same way (Brinkerhoff \& Bossert, 2013). Successful health sector governance is an important pillar for health change (Fryatt, Bennett, \&Soucat, 2017). Various scientists have shifted from a government-centered viewpoint to an interpretation of governance as a human organization of their collective behavior (Meessen, 2020, Samad et al., 2020).

Implementation issues have been linked at the institutional level with insufficient personnel and equipment (Marais \& Petersen, 2015). The concept of good governance is even more serious because " good " is said to be relative. What is considered by the community as good governance, may not be the same as what is considered 'good' by other communities (Madueke, Ololo, \& Emmanuel, 2020). The potential pathway for this higher growth is an increase in labor 
productivity through increased human capital (Nguyen, Giang, Tran, \& Do, 2019). The philosophy of resource dependency deals with external relations and how this can be used to increase expertise and influence (De Regge\&Eeckloo, 2020).

Commitment in an organization reflects the level of closeness of employees (staff) to the company (organization). Those who have a high commitment to the organization are those who feel that they are suitable to work in the organization or company and understand the goals of the organization/company. They will be more productive, proactive, initiative and show great effort for the success of the organization and company. The manifestation of this commitment can be seen from every aspect of the implementation of good hospital governance policies at Undata Hospital based on the results of research that has been done. Where this aspect of commitment is an aspect that cannot be separated from every existing aspect. The commitment aspect is a supporting factor in realizing implementation performance.
In health care, corporate social responsibility means there is an ethical obligation that requires hospitals and other organizations to do something useful on issues such as providing quality health care to everyone who deserves it (Brandão, Rego, Duarte, \& Nunes, 2013). From the data on the performance indicators of medical services at Undata Hospital for the last 3 (three) years, it was quite good, were from the 6 (six) main indicators of inpatient medical services at the hospital, namely: bed occupancy rate (BOR), on the average length of treatment days (Length of Stay / LOS), frequency of bed use (Bed Turn Over / BTO), the average turnover of bed use (Turn Over Interval / TOI), percentage of discharged patients who died (Gross Death Rate / GDR) and the percentage of outgoing patients who died more than 48 hours of treatment (Net Death Rate / NDR) based on data from the Undata Hospital profile in 2018 has met the standard value set by the Ministry of Health. Hospitals are required to include a wide range of facilities across sectors, including chronic care, elderly care services, and other categories of services now considered "integrated care." New hospital-wide initiatives have been implemented in areas such as

Table 1: Medical Service Performance Achievement Indicators Undata Hospital, Central Sulawesi Province 2016-2018

\begin{tabular}{|c|c|c|c|c|c|}
\hline \multirow{2}{*}{ NO } & \multirow{2}{*}{ Indicator } & \multicolumn{3}{|c|}{ Outcomes Every Year } & \multirow{2}{*}{ Standard } \\
\hline & & 2016 & 2017 & 2018 & \\
\hline 1 & Capacity TT & 332 & 350 & 270 & \\
\hline 2 & BOR & $75 \%$ & $52 \%$ & $60 \%$ & $60-85 \%$ \\
\hline 3 & LOS & 5 Day & 5 Day & 5 Day & 6-8 Day \\
\hline 4 & BTO & $37,40 x / y e a r$ & $34 x /$ year & $46 x /$ year & 40-50x/year \\
\hline 5 & TOI & 4,5 Day & 5 Day & 4 Day & 1-3 Day \\
\hline 6 & NDR & $42,82 \%$ & $28 \%$ & $36 \%$ & $25 \%$ \\
\hline 7 & GDR & $29,18 \%$ & $53 \%$ & $62 \%$ & $45 \%$ \\
\hline 8 & Number of patients treated & 11.863 & 12.062 & 12.489 & \\
\hline 9 & Average patients treated every day & 169 & 183 & 202 & \\
\hline 10 & Number of poly visits per year & 144.084 & 73.185 & 74.234 & \\
\hline 11 & Average poly visits per day & 400 & 247 & 264 & \\
\hline 12 & Number of emergency visits per year & 13.571 & 13.937 & 17.358 & \\
\hline 13 & Number of emergency visits per day & 37 & 38 & 47 & \\
\hline 14 & Number of operations & 2.967 & 3.410 & 2.785 & \\
\hline 15 & Number of live births & 630 & 701 & 883 & \\
\hline 16 & Born $<2,5 \mathrm{~kg}$ & 186 & 235 & 302 & \\
\hline 17 & Born $>2,5 \mathrm{~kg}$ & 444 & 466 & 981 & \\
\hline 18 & The patient died $<48$ Hour & 265 & 295 & 323 & \\
\hline 19 & The patient died $>48$ hour & 239 & 342 & 450 & \\
\hline 20 & Abortion & 91 & 141 & 72 & \\
\hline 21 & Number of deliveries & 417 & 441 & 520 & \\
\hline
\end{tabular}

Source: Profile of Undata Hospital, Central Sulawesi Province in 2018. 
quality assurance and patient protection (Durán \&Saltman, 2016). However, it needs to be in line with improving the quality of service to patients, for example, doctor service hours must be on time, patient waiting time is not too long and service administration processes need to be streamlined, where these things are often found based on the results of research conducted by researchers.

Likewise, the data for the last 3 (three) years from the profile of the Undata Hospital in 2018 shows that the number of patient visits at Undata Hospital tends to increase in line with the increasing workload and responsibilities carried out by professionals in it. So that it must be supported by the fulfillment of the rights of every professional who works in the hospital. However, there are several complaints from medical personnel who often experience delays in paying for medical services, which is a problem in implementing an effective, efficient and accountable hospital management system by the mandate of the Hospital Law.

As in the results of this study, the aspects of the Standards and Targets of the Good Hospital Governance Policy at Undata Hospital have performed well with the consistency and clarity of information about the objectives of implementing the policy at Undata Hospital. However, without a strong commitment from owners, directors, and management as well as staff at the hospital, the objectives of implementing hospital governance policies will not be achieved. The level of workforce in a health facility has an impact on the interactions between patient and provider. It seems impossible to improve the relationship between the community and health facilities by simply increasing the number of health workers regardless of the behavior and attitudes of health workers (Mutale et al., 2013). However, not with the resources on the implementation of Good Hospital Governance policies that are still not working properly. This is because several things need to be improved, namely:

1. Human resources, due to the insufficient number of specialist doctors and sub-specialists in Undata Hospital which requires the commitment of the hospital owner, in this case, the Central Sulawesi Provincial Government to support the procurement of specialist doctors and subspecialists by preparing a sufficient budget for the identification of specialist doctors and establish strict regulations for specialist doctors to return to service in their areas of origin who have recommended the education of their specialist doctors and a recruitment system for contract workers that do not yet have clear standards and regulations that require commitment from the board of directors and management to establish these regulations and are committed to fully implementing them. responsible.

2. Budget resources have performed well with accountable financial management and a budget allocation system based on careful planning and involving every stakeholder in Undata Hospital. As a manifestation of the commitment of the board of directors and management to create effective, efficient, and accountable budget governance in the context of realizing good hospital governance at Undata Hospital.

3. Facility resources, due to the lack of attention and slow response of Undata Hospital management in maintaining facilities in the hospital, both in health equipment facilities and health service support facilities such as clogged toilets and damaged and damaged air conditioner $(A C)$. the synergy between the planning of the availability of medical devices with human resources, in this case, the availability of specialists and subspecialists, resulting in ineffective use of these medical devices. And all of them require a strong commitment from the board of directors and management to have responsibility for all facility problems at Undata Hospital.

4. Information resources have been running well as a commitment of all parties in the hospital from the board of directors to the staff level at Undata Hospital in carrying out any hospital accreditation rules that require the availability of information that is easily and quickly accessed by the public.

5. The resources of authority have performed well with the BLUD management system that has been running effectively at Undata Hospital, although it requires a strong commitment to implementing the system with the support of all parties both internally and externally in the hospital. 
Based on the characteristic aspects of the implementing agent, with an emphasis on 2 (two) things, namely the availability of SOPs and the fragmentation or distribution of duties and responsibilities to each implementing agent, they have not performed well because there is no commitment from the parties at Undata Hospital to carry out these SOPs up to the application level, more limited to the availability of SOP administratively to meet accreditation demands in hospitals. This also occurs in the aspect of the attitude/tendency (disposition) of the implementing agent that has not performed well because the discipline of employees at Undata Hospital is only limited to attendance and is not followed by a commitment to run the service properly so that the output of compliance results in disrupted services such as inappropriate service time. Even though in terms of the compliance of medical personnel, paramedics, and administrative officers in providing health services and administrative services at Undata Hospital, it has gone well with outputs that have an impact on patient satisfaction and the patient's family.

Whereas in the aspect of Inter-Organizational Communication it has performed well, especially for internal communication at Undata Hospital, almost all internal policies at Undata Hospital are socialized and coordinated across all staff at the hospital and provide space for participation to all departments and installations at Undata Hospital to get involved. starting from the planning process to the realization of existing programs. Meanwhile, external communication between institutions or agencies still needs to be improved. It takes a strong commitment to all stakeholders to support the implementation of a good hospital governance system at Undata Hospital.

The results of research at the hospital in the implementation of the principles of Good Corporate Governance show that the company still has deficiencies in the implementation of Good Corporate Governance in the principles of transparency, responsibility, and independence where it is not fully transparent regarding financial reports to directors, there are still employees who violate company regulations, salaries that are not by the Regency Minimum Wage, and employees working not according to the job description (Christian Chandra, 2016).

Likewise, the external environmental aspects (economic, social and political) have not performed well because social factors still need to be evaluated in terms of using BPJS membership rights to official families to continue to use their membership rights in accordance with applicable regulations. Although political intervention from hospital owners is almost non-existent, both in terms of filling positions at the hospital and in the planning and budgeting program of Undata Hospital, it is following existing regulations as a form of commitment from hospital owners to realize the principles of good hospital governance in Undata Hospital. Likewise with economic factors in the absence of discriminatory attitudes in providing services at Undata Hospital to patients with different economic backgrounds, including to general patients and BPJS patients as a manifestation of the strong commitment of medical staff and officers at Undata Hospital, Central Sulawesi Province.

\section{CONCLUSION}

The implementation performance of Good Hospital Governance policies at Undata Hospital, Central Sulawesi Province must be supported by the commitment of all parties in the hospital, namely; commitment of owners, directors, and management, as well as all hospital staff, so that the implementation of the Good Hospital Governance policy at Undata Hospital, Central Sulawesi Province can run optimally so that the realization of a hospital with effective, efficient and accountable organizational governance by implementing the principles of transparency, accountability, independence and responsibility, equality and fairness.

\section{ACKNOWLEDGEMENT}

Author most thankful to Tadulako University Research Funding that has provided financial support for the project from which this paper grew.

\section{REFERENCES}

Abdulmalik, J., Kola, L., \& Gureje, O. (2016). Mental health system governance in Nigeria: challenges, opportunities and strategies for improvement. Global Mental Health, 3. https://doi.org/10.1017/gmh.2016.2

Abelson, J., Miller, F. A., \& Giacomini, M. (2009). What does it mean to trust a health system?. A qualitative study of Canadian health care values. Health Policy, 91(1), 63-70. https://doi.org/10.1016/j.healthpol.2008.11.006

Abimbola, S., Negin, J., Martiniuk, A. L., \& Jan, S. (2017). Institutional analysis of health system governance. Health Policy and Planning, 32(9), 1337-1344. https://doi.org/10.1093/heapol/czx083

Afriyie, Stephen O., Kong, Y., Lartey, P. Y., Kaodui, L., Bediako, I. A., Wu, W., \& Kyeremateng, P. H. (2020). Financial performance 
of hospitals: A critical obligation of corporate governance dimensions. International Journal of Health Planning and Management, (July 2019), 1-18. https://doi.org/10.1002/hpm.3049

Afriyie, Stephen Owusu, Kong, Y., Ampimah, B. C., Akuamoah, C. D., Vanderpuije, L. N. O., \& Xinlei, Z. (2020). Verifying the impact of corporate governance on hospital performance on HIV and malaria control: A structural equation modelling approach. International Journal of Health Planning and Management, 35(1), 22-35. https://doi.org/10.1002/hpm.2809

Afriyie, Stephen Owusu, Kong, Y., Danso, P. O., Ibn Musah, A. A., \& Akomeah, M. O. (2019). Do corporate governance mechanisms and internal control systems matter in reducing mortality rates? International Journal of Health Planning and Management, 34(2), 744-760. https://doi.org/10.1002/hpm.2732

Arya, D. (2020). Use of quality management tools and methods is essential to support effective governance of healthcare organisations. Asia Pacific Journal of Health Management, 15(1), 1-4. https://doi.org/10.24083/apjhm.v15i1.325

Brandão, C., Rego, G., Duarte, I., \& Nunes, R. (2013). Social responsibility: A new paradigm of hospital governance? Health Care Analysis, 21(4), 390-402. https://doi.org/10.1007/s10728-012-0206-3

Brinkerhoff, D. W., \& Bossert, T. J. (2013). Health governance: Principal-agent linkages and health system strengthening. Health Policy and Planning, 29(6), 685-693. https://doi.org/10.1093/heapol/czs132

Chandra, C. (2016). Implementasi prinsip-prinsip good corporate governance pada rumah sakit. Agora, 4(1), 869-874 https://doi.org/10.21580/economica.2010.1.1.828

De Regge, M., \& Eeckloo, K. (2020). Balancing hospital governance: A systematic review of 15 years of empirical research. Social Science and Medicine, 262, 113252. https://doi.org/10.1016/j.socscimed.2020.113252

Dixit, S. K. (2017). A new multiperspective emphasis on the public hospital governance. International Journal of Healthcare Management, $0(0), 1-9$. https://doi.org/10.1080/20479700.2017.1403761

Durán, A., \& Saltman, R. B. (2016). Governing Public Hospitals. The Palgrave International Handbook of Healthcare Policy and Governance, 443-461. https://doi.org/10.1007/978-1-137-38493-5 27

Fryatt, R., Bennett, S., \& Soucat, A. (2017). Health sector governance: Should we be investing more? BMJ Global Health, 2(2), 1-7. https://doi.org/10.1136/bmjgh-2017-000343

Gyapong, J. O., Gyapong, M., Yellu, N., Anakwah, K., Amofah, G., Bockarie, M., \& Adjei, S. (2010). Integration of control of neglected tropical diseases into health-care systems: challenges and opportunities. The Lancet, 375(9709), 160165.

https://doi.org/10.1016/S0140-6736(09)61249-6

Hanlon, C., Eshetu, T., Alemayehu, D., Fekadu, A., Semrau, M., Thornicroft, G., ... Alem, A. (2017). Health system governance to support scale up of mental health care in Ethiopia: A qualitative study. International Journal of Mental Health Systems, 11(1), 1-16. https://doi.org/10.1186/s13033-017-0144-4

Houngbo, P. T., Coleman, H. L. S., Zweekhorst, M., De Cock Buning, T., Medenou, D., \& Bunders, J. F. G. (2017). A model for good governance of Healthcare Technology Management in the public sector: Learning from evidence-informed policy development and implementation in Benin. PLOS ONE, 12(1), 1-22.

https://doi.org/10.1371/journal.pone.0168842
Kouam, C. E., Delisle, H., Ebbing, H. J., Israël, A. D., Salpéteur, C., Aïssa, M. A., \& Ridde, V. (2014). Perspectives for integration into the local health system of community-based management of acute malnutrition in children under 5 years: A qualitative study in Bangladesh. Nutrition Journal, 13(1), 115.

https://doi.org/10.1186/1475-2891-13-22

Kuhlmann, E., Rangnitt, Y., \& Von Knorring, M. (2016). Medicine and management: Looking inside the box of changing hospital governance. BMC Health Services Research, 16(2). https://doi.org/10.1186/s12913-016-1393-7

Lempp, H., Abayneh, S., Gurung, D., Kola, L., Abdulmalik, J., EvansLacko, S., ... Hanlon, C. (2018). Service user and caregiver involvement in mental health system strengthening in lowand middle-income countries: A cross-country qualitative study. Epidemiology and Psychiatric Sciences, 27(1), 29-39. https://doi.org/10.1017/S2045796017000634

Lipunga, A. M., Tchereni, B. M. H., \& Bakuwa, R. C. (2019). Emerging structural models for governance of public hospitals. International Journal of Health Governance, 24(2), 98-116. https://doi.org/10.1108/IJHG-03-2019-0018

Madueke, O., Ololo, A. I., \& Emmanuel, E. (2020). Post COVID-19 Pandemic Nigeria: Implications for Good Governance. SSRN Electronic Journal, 5(2), 43-54. https://doi.org/10.2139/ssrn.3632039

Marais, D. L., \& Petersen, I. (2015). Health system governance to support integrated mental health care in South Africa: Challenges and opportunities. International Journal of Mental Health Systems, 9(1). https://doi.org/10.1186/s13033-015-0004-z

Meessen, B. (2020). Health system governance: welcoming the reboot. BMJ Global Health, 5(8), e002404. https://doi.org/10.1136/bmjgh-2020-002404

Mikkelsen-Lopez, I., Wyss, K., \& De Savigny, D. (2011). An approach to addressing governance from a health system framework perspective. BMC International Health and Human Rights, 11(1). https://doi.org/10.1186/1472-698X-11-13

Moro Visconti, R., \& Martiniello, L. (2019). Smart hospitals and patient-centered governance. Corporate Ownership and Control, 16(2), 83-96. https://doi.org/10.22495/cocv16i2art9

Mutale, W., Bond, V., Mwanamwenge, M. T., Mlewa, S., Balabanova, D., Spicer, N., \& Ayles, H. (2013). Systems thinking in practice: The current status of the six WHO building blocks for health system strengthening in three BHOMA intervention districts of Zambia: A baseline qualitative study. BMC Health Services Research, 13(1), 1-9. https://doi.org/10.1186/1472-6963-13-291

Nguyen, C. V., Giang, L. T., Tran, A. N., \& Do, H. T. (2019). Do Good Governance and Public Administration Improve Economic Growth and Poverty Reduction? The Case of Vietnam. International Public Management Journal, O(0), 1-27. https://doi.org/10.1080/10967494.2019.1592793

Oleribe, O. O., Momoh, J., Uzochukwu, B. S. C., Mbofana, F., Adebiyi, A., Barbera, T., ... Taylor-Robinson, S. D. (2019). Identifying key challenges facing healthcare systems in Africa and potential solutions. International Journal of General Medicine, 12, 395-403. https://doi.org/10.2147//JGM.S223882

Pasinringi, A., Samad, M. A., Alamsyah, M. N., \& Jeni. (2020). Public Health Policy in Donggala Regency. Technium Social Sciences Journal, 11, 1 . https://doi.org/10.47577/tssj.v11i1.1509

Pyone, T., Smith, H., \& Van Den Broek, N. (2017). Frameworks to assess health systems governance: A systematic review. Health Policy and Planning, 32(5), 710-722. https://doi.org/10.1093/heapol/czx007 
Samad, M. A., Zuada, L. H., \& Baculu, V. A. Is. (2020). Implementation of E-Government Policies: Case Study of Goods and Services Procurement in Buol Regency, Central Sulawesi. Proceedings of the 2nd Annual International Conference on Business and Public Administration (AICoBPA 2019). 2nd Annual International Conference on
Business and Public Administration (AICoBPA 2019), Malang, Indonesia.

https://doi.org/10.2991/aebmr.k.201116.015

Van Olmen, J., Marchal, B., Van Damme, W., Kegels, G., \& Hill, P. S. (2012). Health systems frameworks in their political context: Framing divergent agendas. BMC Public Health, 12(1), 3-6. https://doi.org/10.1186/1471-2458-12-774

Received on 14-01-2021

Accepted on 16-02-2021

Published on 22-02-2021

DOI: https://doi.org/10.6000/1929-4409.2021.10.64

(C) 2021 Tjaija et al.; Licensee Lifescience Global.

This is an open access article licensed under the terms of the Creative Commons Attribution Non-Commercial License (http://creativecommons.org/licenses/by-nc/3.0/) which permits unrestricted, non-commercial use, distribution and reproduction in any medium, provided the work is properly cited. 